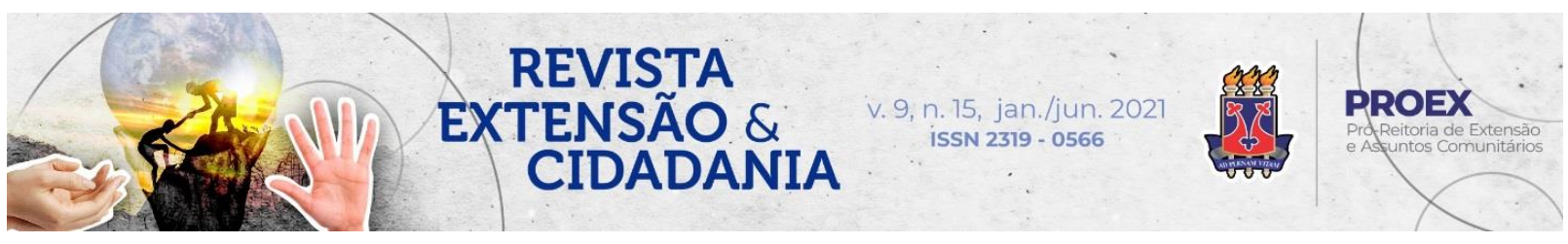

DOI: $10.22481 /$ recuesb.v9i15.8162

\title{
EDUCAÇÃO MATEMÁTICA PARA E COM IDOSOS EM TEMPOS DE PANDEMIA
}

\author{
Mathematics Education for and with elderly people during a pandemic situation
}

\author{
Ronaldo André Lopes ${ }^{1}$ \\ Rejane Siqueira Julio ${ }^{2}$ \\ Guilherme Henrique Gomes da Silva ${ }^{3}$ \\ Rafael Ferreira Cardoso ${ }^{4}$ \\ Sara Maria Fagundes Conti Neves ${ }^{5}$
}

Resumo: O projeto de extensão Conversas Matemáticas desenvolve atividades pedagógicas envolvendo matemática para e com pessoas idosas na Universidade Federal de Alfenas. Neste artigo, abordamos novas formas de construir e executar um projeto extensionista em tempos de pandemia, considerando o desenvolvimento do Conversas Matemáticas no ano de 2020, bem como as avaliações das participantes e suas expectativas em relação à edição de 2021. Em 2020, a equipe elaborou e desenvolveu vinte atividades remotamente para e com dezessete idosas, utilizando um grupo de Whatsapp para as interações e realizando entrega de algumas atividades impressas em seus domicílios. Também foram feitas ligações de áudio para manter o contato com as idosas e para conversar sobre suas vivências pessoais durante a pandemia. Como resultado, as participantes apontaram a importância do projeto para suas vidas, uma vez que possibilitou que se mantivessem ativas e permitiu a criação de um senso de pertencimento ao grupo, proporcionando alegria e aprendizado. Além disso, as idosas destacaram aspectos relevantes para a execução do projeto em 2021, com interesse pela continuidade das atividades. Concluímos que o projeto tem impactado positivamente a vida das idosas, viabilizando a inclusão social e a interação dialógica.

\footnotetext{
${ }^{1}$ Mestrando em Educação, pela Universidade Federal de Alfenas, Alfenas, Minas Gerais, Brasil. Orcid: 00000001-7215-7101. E-mail: ronaldoalopes1998@gmail.com

${ }^{2}$ Doutora em Educação Matemática, pela Universidade Estadual Paulista Júlio de Mesquita Filho (Unesp). Professora Adjunta de Matemática, da Universidade Federal de Alfenas (UNIFAL-MG); Professora do Programa de Pós-graduação em Educação, da Universidade Federal de Alfenas (UNIFAL-MG), Alfenas, Minas Gerais, Brasil. Orcid: 0000-0002-3248-800X. E-mail: rejane.julio@unifal-mg.edu.br

${ }^{3}$ Doutor em Educação Matemática, pela Universidade Estadual Paulista Júlio de Mesquita Filho (Unesp). Professor Adjunto de Matemática, da Universidade Federal de Alfenas (UNIFAL-MG); Professor do Programa de Pós-graduação em Educação, da Universidade Federal de Alfenas (UNIFAL-MG), Alfenas, Minas Gerais, Brasil. Orcid: 0000-0002-4166-2663. E-mail: guilherme.silva@unifal-mg.edu.br

${ }^{4}$ Graduando do curso de Licenciatura em Matemática, pela Universidade Federal de Alfenas, Alfenas, Minas Gerais, Brasil. Orcid: 0000-0002-8439-0717. E-mail: rafael.cardoso@ sou.unifal-mg.edu.br

${ }^{5}$ Graduanda do curso de Licenciatura em Matemática, pela Universidade Federal de Alfenas, Alfenas, Minas Gerais, Brasil. Orcid: 0000-0002-6558-599X. E-mail: saracontineves@ hotmail.com
} 
Palavras-chave: Isolamento Social. Covid-19. Idosos. Educação Matemática. Extensão Universitária.

Abstract: The Conversas Matemáticas extension project develops pedagogical activities involving mathematics contents for and with elderly people at Federal University of Alfenas. In this article, we discuss new ways of composing an extension project in a pandemic time. We explore the development of Conversas Matematicas during 2020 year as well as the participants' evaluations of the project, including their expectations regarding the 2021 project edition. In 2020 edition, the project team elaborated and developed twenty activities remotely for and with seventeen elderly women. We used WhatsApp group for interactions and delivery printed activities at their homes. We used WhatsApp audio to keep in touch, and to talk about their personal experiences during the pandemic. As a result, the participants pointed out the importance of the project in their lives, which allowed them to remain active and allowed them to feel a sense of belonging to the group. It provided joy and learning. In addition, the elderly women highlighted relevant aspects for the execution of the project in 2021, with an interest in the continuity of activities. We conclude that the project has positively impacted their lives, enabling social inclusion and dialogical interaction.

Keywords: Social Isolation. Covid-19. Elderly People. Mathematics Education. Extension University.

\section{Introdução}

O que uma educação matemática para e com idosos pode significar? Certamente há várias respostas para essa questão. Para nós, ela pode significar a criação de oportunidades de produção de conhecimentos, de reivindicação de direitos, de maior participação na sociedade, de luta por justiça social e oportunidade para estar junto com outras pessoas (SKOVSMOSE, 2017; JULIO; SILVA, 2019; LIMA; PENTEADO; SILVA, 2019). Nesse sentido, o projeto de extensão Conversas Matemáticas foi desenvolvido visando o favorecimento da interação social e da possibilidade de pessoas idosas utilizarem a matemática como uma oportunidade para se manterem ativas. Nele, são desenvolvidas atividades envolvendo matemática para e com pessoas idosas, com diferentes formações e experiências de vida. Além disso, o projeto contribui para o atendimento de uma demanda da sociedade por políticas públicas e ações destinadas às pessoas idosas, advindas do envelhecimento da população brasileira (SIMÕES, 2016). Ele integra o programa Universidade Aberta à Terceira Idade (UNATI), que busca desenvolver atividades de diferentes tipos que estimulem a autonomia no viver e a qualidade de saúde física e mental da pessoa idosa.

Revista Extensão \& Cidadania, v. 9, n. 15, p. 27-45, jan./jun. 2021. 
De um projeto feito, inicialmente, para pessoas idosas, ele se tornou um projeto com pessoas idosas. A participação no projeto é predominantemente de mulheres e, logo no início do desenvolvimento das atividades, elas fizeram sugestões e apontaram demandas como, por exemplo, de se discutir sobre questões financeiras e fractais. Além disso, as próprias vivências e conhecimento de mundo delas foram moldando nossa forma de construir e executar o projeto. Isso é inerente quando falamos em ações extensionistas, em particular, nas diretrizes extensionistas como a interação dialógica, "marcada pelo diálogo, pela ação de mão-dupla, de troca de saberes, de superação do discurso da hegemonia acadêmica" (FORPROEX, 2007, p. 18). Com a pandemia provocada pelo vírus Sars-Cov-2, em 2020, e a necessidade de distanciamento/isolamento social para a preservação de vidas, foram requeridas novas formas de construir e executar um projeto extensionista dedicado às pessoas idosas, o que é uma novidade em termos de extensão universitária e também no âmbito da pesquisa.

Este trabalho é fruto da indissociabilidade entre ensino, pesquisa e extensão, no qual executamos atividades educativas com pessoas idosas e produzimos pesquisas relacionadas ao projeto, como é o caso de estudos envolvendo a formação de professores de matemática (SILVA; SILVA; JULIO, 2021), interação em tempos de pandemia (CARDOSO et al., 2021), inclusão social (SILVA; JULIO, 2018), avaliação do projeto pelas idosas participantes (JULIO; SILVA, 2019) e uso de tecnologias e materiais manipulativos (LOPES; SILVA; JULIO, 2020). As ações são desenvolvidas por meio da observação participante, que permite o envolvimento do pesquisador com a situação, favorecendo totalmente a imersão na realidade explorada (LUDKE; ANDRÉ, 1986).

Em particular, neste trabalho, nosso objetivo é abordar novas formas de construir e executar um projeto extensionista em tempos de pandemia, destacando a transformação ocorrida no projeto Conversas Matemáticas. Para isso, discutimos a forma como ele foi desenvolvido no decorrer de 2020 e nas versões anteriores, destacando algumas particularidades e nossos referenciais teóricos, e discutimos sobre as avaliações realizadas durante e no final da versão 2020 do projeto e as expectativas das idosas para o ano de 2021 .

\section{O projeto Conversas Matemáticas}

O projeto de extensão Conversas Matemáticas acontece desde 2017 na Universidade Federal de Alfenas e, desde 2018, faz parte do Programa Universidade Aberta à Terceira Idade

Revista Extensão \& Cidadania, v. 9, n. 15, p. 27-45, jan./jun. 2021. 
(UNATI), que possui projetos direcionados à saúde, à educação e ao bem-estar da população idosa da cidade de Alfenas e região. O Conversas Matemáticas busca desenvolver uma educação matemática visando promover a interação social, a produção de conhecimentos matemáticos e de outros conhecimentos e a oportunidade para que pessoas idosas se mantenham ativas. Para isso, são utilizadas diferentes metodologias, como o uso e a construção de materiais manipulativos, de jogos pedagógicos e a criação de cenários para investigações matemáticas.

Antes de 2020, as ações do projeto ocorriam no Laboratório de Educação Matemática da Universidade Federal de Alfenas, em encontros semanais com duração de duas horas e contava com cerca de dez idosas participantes em cada encontro. Além dos encontros semanais, algumas interações relacionadas ao projeto ocorriam por meio de um grupo no Whatsapp, criado para recados e avisos. A equipe do projeto se reunia semanalmente para discutir sobre as ações ocorridas e as que seriam desenvolvidas.

Em 2020, haviam 17 idosas inscritas no projeto e não houve inscrição de idosos do sexo masculino, ainda que o projeto seja aberto a este público. Devido à pandemia, a equipe optou por desenvolver as atividades remotamente e se deparou com alguns desafios, como, por exemplo, o de motivar um grupo de idosas resistentes ao uso de tecnologias a participarem do projeto, como descrito em Silva, Silva e Julio (2019) e Lopes, Silva e Julio (2020). Como já havia algum tipo de interação pelo grupo de Whatsapp, como mensagens em datas comemorativas, convites para seção de cinema e para tomar sorvete, optamos por utilizar esta plataforma como um meio de comunicação mais efetivo, se tornando um espaço para a realização das atividades.

Assim, mantivemos nossos pressupostos de tentativa de criação de cenários para investigação, em que as idosas são convidadas a participarem de atividades envolvendo investigações matemáticas, como preconiza Skovsmose (2000). Nesse contexto, elas são incentivadas a formularem questões e a procurarem explicações para as atividades que estão realizando, sejam elas lúdicas, manipulativas, dentre outras que apresentam problemas a serem investigados. Não há constituição de cenários para investigação se não houver diálogo, que é entendido como uma forma de interação entre os sujeitos envolvidos no projeto, engajados em uma atividade de aprendizagem "em que a fala e a escuta ativa são compartilhadas, ideias são discutidas e a compreensão do que o outro diz é fundamental" (MILANI, 2017, p. 50). Não se trata somente de uma conversa entre sujeitos biológicos, mas da tentativa de compartilhamento de interlocutores (seres cognitivos), de direções de falas, na qual acreditamos que um

Revista Extensão \& Cidadania, v. 9, n. 15, p. 27-45, jan./jun. 2021. 
interlocutor diria o que outro está dizendo e aceitaria/adotaria a justificação que autoriza a dizer o que este outro está dizendo (LINS, 1999).

Mantivemos, também, as orientações de Lima (2015), que sugere algumas adaptações para o trabalho com o público idoso, como a utilização de figuras com contornos e delineações fortes, o uso de letras em tamanho maior, presença de falas pausadas, bem como a utilização de uma linguagem objetiva e em volume adequado. No entanto, para mantermos esses pressupostos, foi necessário retomarmos as leituras de Skovsmose (2000) e Lins (1999) pensando em possibilidades para o desenvolvimento do projeto no formato remoto e adotando, por exemplo, o uso de mensagens de texto, vídeos, imagens e áudios como tentativas de interação com as idosas. O ano de 2020 representou, assim, o esforço de tentar constituir cenários para investigação em um ambiente remoto no qual produções de significados fossem incentivadas e pudesse acontecer a produção de conhecimentos, já que toda fala/produção de significado implica em produção de algum conhecimento (LINS, 1999), e de continuar proporcionando a interação social, conseguida em anos anteriores.

Desta maneira, adaptamos nossa forma de pensar as atividades e interagir com as 17 idosas participantes no nosso grupo de Whatsapp, executando o projeto em três frentes: postagem e interação constante pelo Whatsapp (no grupo, prioritariamente, ou de forma individual), entrega de atividades impressas em casa e ligações para as idosas. As atividades das duas primeiras frentes foram sintetizadas no Quadro 1, no qual são especificadas quais foram realizadas pelo Whatsapp, em domicílio ou nos dois ambientes, por meio de imagens ilustrativas. Nas próximas seções, abordamos cada uma dessas frentes. Cabe dizer que as reuniões da equipe também passaram a acontecer de forma remota, semanalmente, e as discussões sobre as atividades realizadas e a serem executadas, bem como estratégias de condução do projeto, ocorreram também pelo WhatsApp e pelo Google Meet. Destacamos ainda que, para preservar o anonimato das participantes do projeto, usamos os seguintes nomes fictícios para as idosas que mencionamos neste artigo: Elza, Fátima, Inês, Orminda, Sônia, Magda, Ivone, Lázara, Cristina, Sandra, Stela e Amélia.

Revista Extensão \& Cidadania, v. 9, n. 15, p. 27-45, jan./jun. 2021. 
Quadro 1 - Atividades realizadas em 2020

\begin{tabular}{|c|c|c|c|}
\hline $\mathbf{N}^{\circ}$ & Atividade & Objetivos & Tipo \\
\hline 01 & $\begin{array}{l}\text { História dos } \\
\text { Números }\end{array}$ & $\begin{array}{l}\text { Conhecer um pouco sobre a origem dos números e } \\
\text { problematizar nosso atual modo de representação numérica. }\end{array}$ & 8 \\
\hline 02 & Jogo Resta Um & $\begin{array}{l}\text { Desenvolver o domínio espacial e a concentração através do } \\
\text { jogo Resta Um. }\end{array}$ & (c) \\
\hline 03 & Desafio dos Pesos & $\begin{array}{l}\text { Resolver sistemas de equações por meio de desafios que } \\
\text { envolvem a pesagem de alimentos. }\end{array}$ & (6) \\
\hline 04 & História do Zero & Conhecer a origem e a história do número zero. & (c) \\
\hline 05 & Jogo Tangram & $\begin{array}{l}\text { Confeccionar o jogo Tangram e, através dele, compreender } \\
\text { conceitos como área e perímetro de figuras planas. }\end{array}$ & (6) \\
\hline 06 & Desafio Equações & Resolver equações de primeiro grau com desafios ilustrados. & C \\
\hline 07 & Poema Matemático & $\begin{array}{l}\text { Discutir sobre conceitos matemáticos a partir de um poema } \\
\text { temático. }\end{array}$ & (c) \\
\hline 08 & $\begin{array}{l}\text { Quebra-Cabeças } \\
\text { com Hexágonos }\end{array}$ & $\begin{array}{l}\text { Construir triângulos equiláteros de diferentes cores e em níveis } \\
\text { diferentes de complexidade por meio de um quebra-cabeça } \\
\text { hexagonal subdividido em seis cores distintas. }\end{array}$ & 金 \\
\hline 09 & $\begin{array}{l}\text { Jogo das Quatro } \\
\text { Cores }\end{array}$ & $\begin{array}{l}\text { Confeccionar o jogo das quatro cores e realizar os desafios } \\
\text { propostos. }\end{array}$ & (1) 金 \\
\hline 10 & $\begin{array}{l}\text { Curiosidades da } \\
\text { Tabuada no } 9\end{array}$ & $\begin{array}{l}\text { Investigar algumas particularidades da Tabuada do Nove e } \\
\text { realizar discussões sobre a tabuada. }\end{array}$ & (6) \\
\hline 11 & $\begin{array}{l}\text { Jogo Dominó das } \\
\text { Quatro Cores }\end{array}$ & $\begin{array}{l}\text { Desenvolver o raciocínio lógico a partir do jogo Dominó das } \\
\text { Quatro Cores. }\end{array}$ & $\widehat{\hat{1}}$ \\
\hline 12 & $\begin{array}{l}\text { Questionário } \\
\text { Matemática } \\
\text { Financeira }\end{array}$ & $\begin{array}{l}\text { Aprender sobre alguns conceitos que envolvem a matemática } \\
\text { financeira através de um questionário adaptado da OBEF } \\
\text { (Olimpíada Brasileira de Educação Financeira). }\end{array}$ & (C) \\
\hline 13 & $\begin{array}{l}\text { Primeiros passos } \\
\text { nos investimentos }\end{array}$ & $\begin{array}{l}\text { Vídeo sobre Educação Financeira realizado pelo coordenador } \\
\text { do projeto de extensão Futuro sem Fatura. }\end{array}$ & (6) \\
\hline 14 & Matemágica & $\begin{array}{l}\text { Conhecer curiosidades matemáticas envolvendo a resolução } \\
\text { de expressões algébricas. }\end{array}$ & ( \\
\hline 15 & $\begin{array}{l}\text { Combinando } \\
\text { Números com } \\
\text { Hexágonos }\end{array}$ & $\begin{array}{l}\text { Solucionar um quebra-cabeça numérico com peças } \\
\text { hexagonais. e resolver o Hexágono Mágico utilizando } \\
\text { operações básicas. }\end{array}$ & 金 \\
\hline 16 & $\begin{array}{l}\text { Jogo Hexágono } \\
\text { Mágico e Quadrado } \\
\text { mágico }\end{array}$ & $\begin{array}{l}\text { Completar com números de } 1 \text { a } 19 \text { um hexágono de forma que } \\
\text { os elementos das linhas verticais e diagonais tenham soma } \\
\text { igual a } 38 \text {. Relembrar a atividade sobre Quadrado Mágico. }\end{array}$ & $\hat{\mathrm{I}}$ \\
\hline 17 & Jogo Tchuka & $\begin{array}{l}\text { Confeccionar o Jogo Tchuka e desenvolver o raciocínio lógico } \\
\text { através da prática. }\end{array}$ & C \\
\hline 18 & Jogo do L & $\begin{array}{l}\text { Utilizar as transformações geométricas (rotação, translação e } \\
\text { reflexão) e a simetria através da resolução do Jogo do L. }\end{array}$ & 10 \\
\hline 19 & Avaliação Final & $\begin{array}{l}\text { Apresentar uma avaliação da equipe sobre o projeto e solicitar } \\
\text { uma avaliação dele pelas idosas participantes. }\end{array}$ & (C) \\
\hline 20 & Caderno de Férias & $\begin{array}{l}\text { Relembrar as atividades desenvolvidas durante o ano e } \\
\text { desenvolver outras atividades no período de férias para as } \\
\text { idosas se manterem em atividade. }\end{array}$ & 金 \\
\hline
\end{tabular}

Fonte: Elaborado pelos autores.

Revista Extensão \& Cidadania, v. 9, n. 15, p. 27-45, jan./jun. 2021.

ISSN 2319-0566 DOI: 10.22481/recuesb.v9i15.8162 


\section{O uso do WhatsApp como plataforma de postagem e interação}

O grupo de WhatsApp com as idosas foi criado inicialmente para recados e mensagens (como convites para cinema e sobre datas comemorativas) e se tornou, em 2020, nossa principal plataforma de postagem de atividades e interação com elas. As atividades eram enviadas toda quarta-feira pela manhã. Para a elaboração delas, a equipe optou por confeccionar vídeos curtos, como: "História dos Números" e "História do Zero", que abordavam temas sobre a história da matemática com questionamentos acerca da possibilidade de, no futuro, termos outro tipo de escrita numérica, diferente dos algarismos indo-arábicos, por exemplo. Em outros, sugeria a elaboração de materiais manipulativos, como o Jogo Tangram e o Jogo Resta Um e, em seguida, propunha o uso deles com exibição do passo a passo de construção, regras e modo de utilização. Os dois vídeos foram finalistas do Festival de Vídeos e Educação Matemática, ocorrido em 2020, e podem ser acessados pelos seguintes links:

https://www.youtube.com/watch?v=yMmqk_PAd1w https://www.youtube.com/watch?v=P_DFHyC_cfM.

Como alguns membros da equipe já conheciam as idosas e sabiam que elas gostavam de confeccionar jogos e materiais, mantivemos e intensificamos essa prática. Um dos obstáculos encontrados pela equipe organizadora foi a padronização de materiais e dos métodos de confecção. A solução encontrada, portanto, baseou-se na utilização de materiais recicláveis, visando a maior abrangência de disponibilidade entre as idosas, o que abriu margem para um desenvolvimento criativo das participantes ao adaptarem os modelos apresentados pela equipe. Um bom exemplo disso foi a atividade 9 (“Jogo das Quatro Cores”), na qual a ideia inicial era de que o tabuleiro do jogo fosse confeccionado com papelão e as peças com tampas de garrafa PET, como na imagem à esquerda a seguir:

Figura 1 - Jogo das Quatro Cores confeccionado pela equipe do projeto Conversas Matemáticas utilizando materiais recicláveis
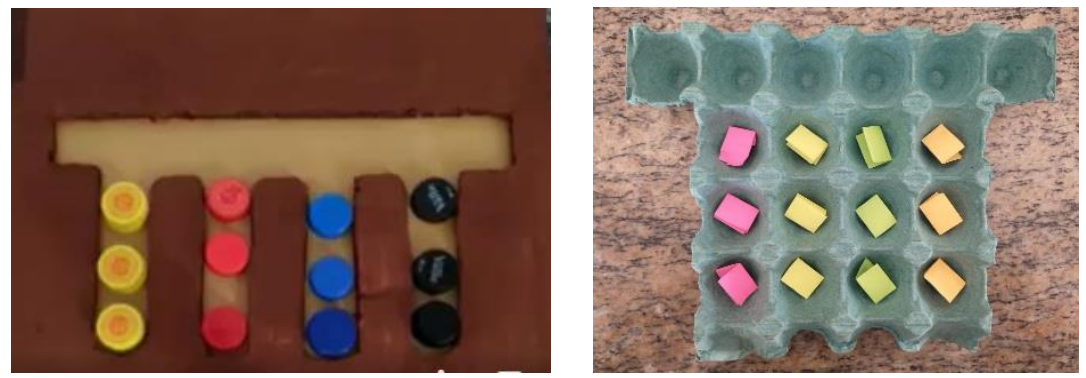

Fonte: Elaborado pelos autores.

Revista Extensão \& Cidadania, v. 9, n. 15, p. 27-45, jan./jun. 2021. 
Para mostrarmos às idosas que o jogo poderia ser confeccionado de diferentes modos, enviamos também uma imagem que mostrava que ele poderia ser montado utilizando uma caixa de ovos (Figura 1 - imagem à direita). Dessa forma, elas se sentiriam mais à vontade para adaptar o jogo com os objetos que tinham em suas casas. As participantes enviaram fotos dos jogos e nenhuma delas confeccionou exatamente como foi proposto, o que nos surpreendeu de início e nos alegrou no decorrer da atividade, como pode ser visto na Figura 2. Deparamo-nos com a substituição do papelão por caixa de água de coco, folhas de sulfite e cartolinas, e das tampas de garrafa por botões, moedas e rolhas. As adaptações foram recebidas positivamente pela equipe, que incentivou as práticas criativas.

Figura 2 - Jogo das Quatro Cores elaborado pelas idosas com materiais recicláveis e reutilizáveis que elas tinham em casa

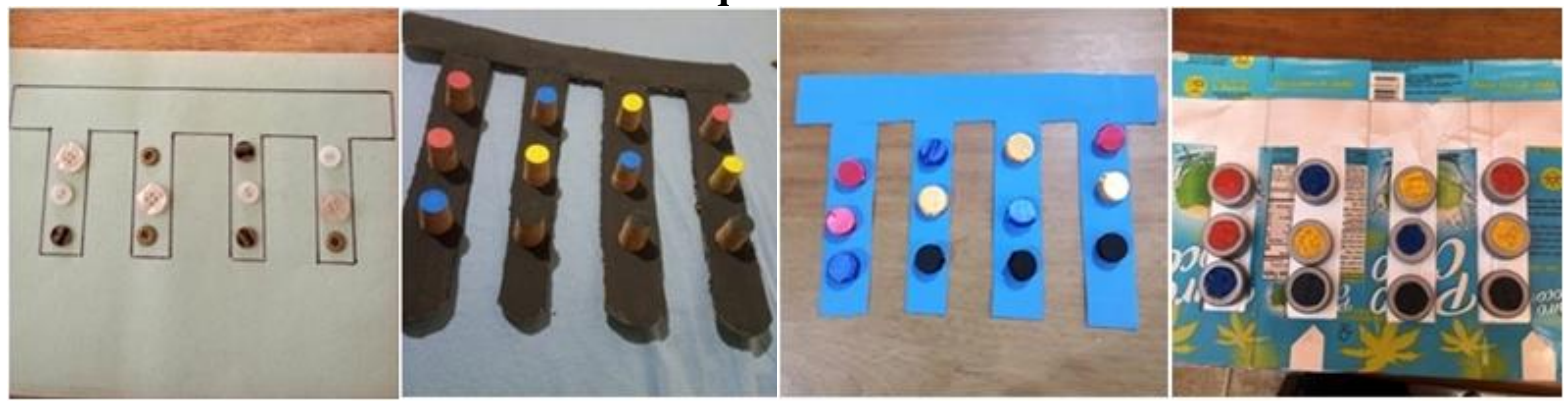

Fonte: Elaborado pelos autores.

Ao realizarem essas atividades de confecção de materiais, assim como as demais, as idosas encaminhavam fotos, áudios, vídeos, dúvidas e suas considerações para todos no grupo de Whatsapp, ou então, para um dos membros da equipe de forma privada.

\section{Ligações para as idosas participantes}

Com a proposta de execução do Conversas Matemáticas no formato remoto, observamos uma queda no envolvimento das participantes nos meses iniciais do projeto. A partir disso, realizamos ligações por telefone para compreender o vínculo estabelecido pelas idosas com o projeto em um ano atípico e as demandas em relação às atividades. Devido à pandemia, poucos projetos de extensão da Universidade Federal de Alfenas continuaram em execução, como foi o caso do projeto Conversas Matemáticas, foco deste trabalho.

Revista Extensão \& Cidadania, v. 9, n. 15, p. 27-45, jan./jun. 2021. 
Ao receberem nossas ligações, as idosas se sentiam surpresas e acolhidas, vendo essa ação como uma oportunidade de desabafar e de estar perto da equipe. De forma unânime, as idosas alegaram que preferiam que as atividades fossem entregues em casa, mas que participariam das interações no Whatsapp. Durante as conversas pelo telefone, algumas idosas apontaram situações difíceis vivenciadas durante a pandemia, como o cancelamento da aposentadoria (Elza), o fato de se sentir triste e solitária (Fátima) e o medo e o pânico com a COVID-19 (Fátima e Inês).

Em relação ao uso das tecnologias digitais, Fátima e Stela afirmaram que possuíam dificuldade de acesso à internet por residirem na zona rural. Já Sônia destacou que se sentia sobrecarregada com o uso excessivo do celular e que, por este motivo, evitava ficar muito tempo utilizando o smartphone. Ivone também alegou desinteresse em utilizar o Whatsapp com grande frequência, pois tem dificuldade para digitar e ler as mensagens. Entretanto, ela realizava a leitura e participava das discussões semanalmente. A fé também foi um fator apresentado pelas idosas para o enfrentamento à situação de pandemia, como apontado por Orminda e Inês, que têm feito orações e rezado terços com frequência.

Relembrando as vivências de 2018 e 2019 no projeto, algumas idosas destacaram o quanto a socialização e a participação nas atividades presenciais eram importantes. Inês, por exemplo, disse que possuía um arquivo do projeto, onde guardava todas as atividades que já fez e, em alguns momentos, as retomavam e bagunçava o material para relembrar o que aprendeu. E Sandra destacou que a participação no projeto em 2019 permitia que ela saísse outra pessoa após as atividades, evidenciando o potencial da convivência com as colegas idosas. Stela disse, no decorrer de uma das ligações, que a ausência de alguém cobrando a realização das atividades fazia falta e que, por isso, seria importante que não fosse cessado totalmente o projeto, mantendo a interação de forma remota. Sônia afirmou que se sentia mais preguiçosa durante o isolamento social e menos ativa do que nas aulas presenciais. Magda disse que estava torcendo para que as aulas retornassem ainda em 2020. Orminda disse que havia perdido a coragem durante a pandemia e que ficou sem vontade de fazer as atividades do dia a dia. Elza disse que, no formato remoto, era mais difícil tirar dúvidas e que se sentia mais tímida pelo Whatsapp.

Após as ligações, houve um feedback positivo das idosas em relação à participação no projeto. Com a postagem semanal de atividades pelo Whatsapp, as idosas manifestavam o interesse não somente pela resolução ou prática, mas também, pela interação social e pelo senso de pertencimento ao grupo. Neste sentido, Stela disse que as atividades se mostravam como

Revista Extensão \& Cidadania, v. 9, n. 15, p. 27-45, jan./jun. 2021. 
possibilidades para ela se desligar da realidade em que estava inserida, sendo um momento de distração e de paz. Já Cristina afirmou que se sentia menos solitária com as atividades e com o contato com a equipe e com as colegas. Em especial, essa participante foi a que mais buscou conversar com os integrantes da equipe e interagir com as colegas, tanto no grupo quanto por meio de mensagens privadas. Elza também destacou a importância de pertencer ao grupo Conversas Matemáticas, alegando que independentemente da quantidade de atividades que ela fazia, esse pertencimento tornava a vida dela mais feliz.

\section{Entrega das atividades em casa}

Devido à demanda das idosas por telefone, uma vez por mês, realizamos a entrega de uma atividade em suas casas, tomando todos os cuidados de distanciamento e com a higienização dos materiais. Algumas idosas solicitaram, ainda, que a entrega fosse feita por parte da equipe, para que pudessem ter um contato visual com os integrantes pelo menos uma vez por mês. De modo mais específico, essas atividades consistiam em jogos e, após recortarem o material ou então somente manuseá-lo, postavam as fotos do que haviam feito no grupo. Um exemplo pode ser visto na Figura 3, para a atividade "Quebra-cabeça com Hexágonos":

Figura 3 - Jogo Quebra-cabeça com hexágonos manipulado pelas idosas

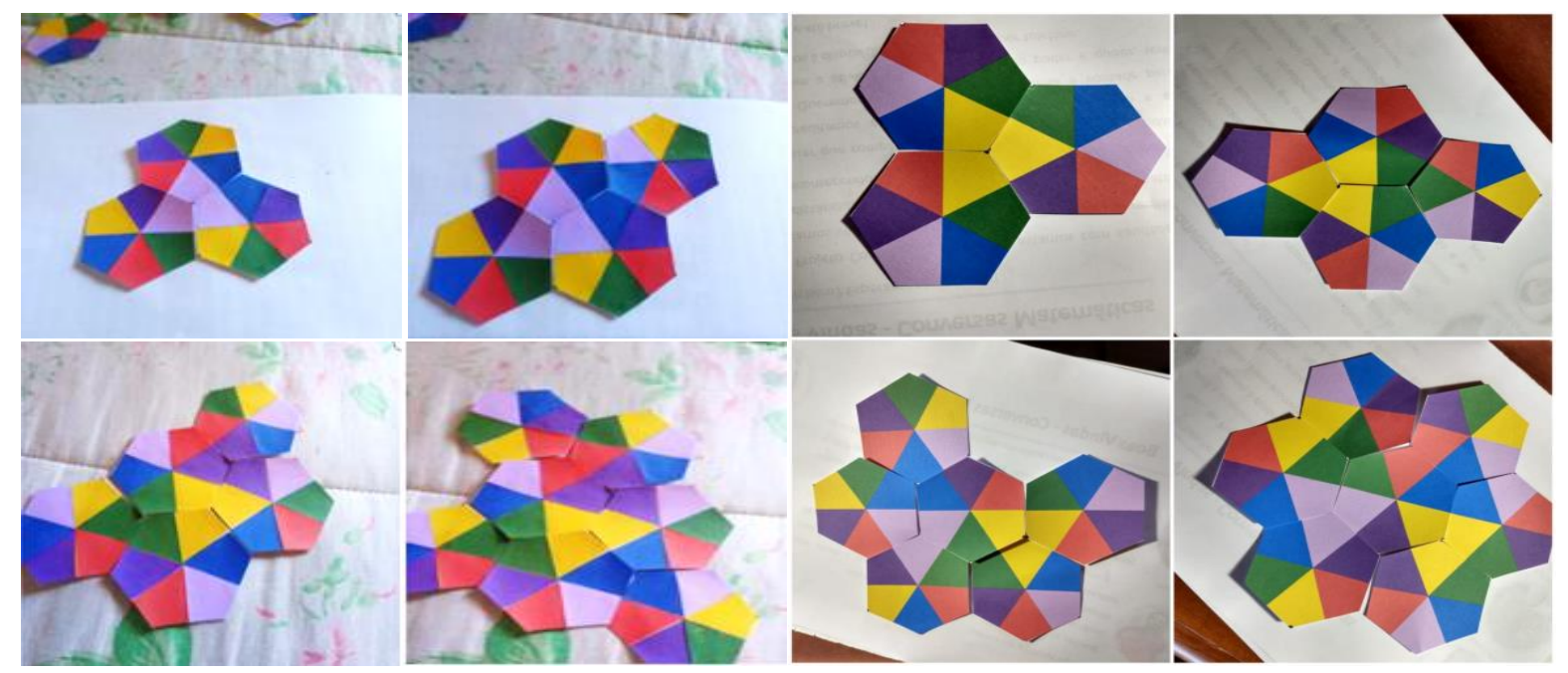

Fonte: Elaborado pelos autores.

Foram diversas as manifestações positivas das idosas em relação às atividades entregues em casa. Sônia e Stela afirmaram que se sentiam alegres ao receber cada atividade e que isso fazia a diferença nos dias monótonos de quarentena. As participantes também ficavam ansiosas,

Revista Extensão \& Cidadania, v. 9, n. 15, p. 27-45, jan./jun. 2021. 
aguardando a atividade e, quando a recebiam, agradeciam a dedicação, o capricho e o carinho da equipe. A entrega de atividades em casa promoveu, ademais, uma maior interação entre os membros de uma mesma família. Isso foi expresso por Elza, que afirmou que o marido realizava a leitura dos materiais entregues e a ajudava na resolução e manipulação das atividades propostas. Amélia, que aprendeu uma curiosidade sobre a tabuada do número nove, disse que ensinaria ao seu neto. E, na casa de Cristina, sua irmã também participou de algumas atividades, sendo que, até 2019, ela não conhecia as atividades e dizia que Cristina participava de um projeto em que construía "brinquedinhos" e "joguinhos fáceis".

\section{Avaliação final das idosas em relação ao Conversas Matemáticas}

Para encerrar o projeto em 2020, a equipe gravou um vídeo de despedida para as idosas. Devido à pandemia, elas não conheceram todos os integrantes pessoalmente neste ano e, por isso, o vídeo surgiu como uma alternativa de contato mais próximo com as participantes. Neste vídeo, também foram elencadas perguntas para uma avaliação final do projeto, algo que sempre ocorria, só que de forma presencial e por meio de dinâmicas. As perguntas foram:

1. O que vocês acharam do projeto em 2020?

2. Quais conselhos vocês dariam para a equipe do Conversas Matemáticas?

3. O que vocês mudariam nas atividades do projeto?

4. O que esperam para 2021 ?

5. Se o projeto continuasse de forma remota, pelo WhatsApp, vocês iriam gostar?

6. Quais foram os maiores desafios nesse ano? Alguma coisa ficou mais fácil?

7. Como foi receber as atividades em casa?

Para que as idosas não precisassem retomar o vídeo para acessar às perguntas, nós as redigimos e disponibilizamos no grupo de Whatsapp. Dentre as idosas, oito responderam à avaliação final. A Figura 5 exibe algumas respostas das participantes às perguntas 1, 2 e 3, respectivamente.

Revista Extensão \& Cidadania, v. 9, n. 15, p. 27-45, jan./jun. 2021. 


\section{Figura 5 - Respostas das idosas em relação às perguntas 1, 2 e 3 na avaliação final do projeto}

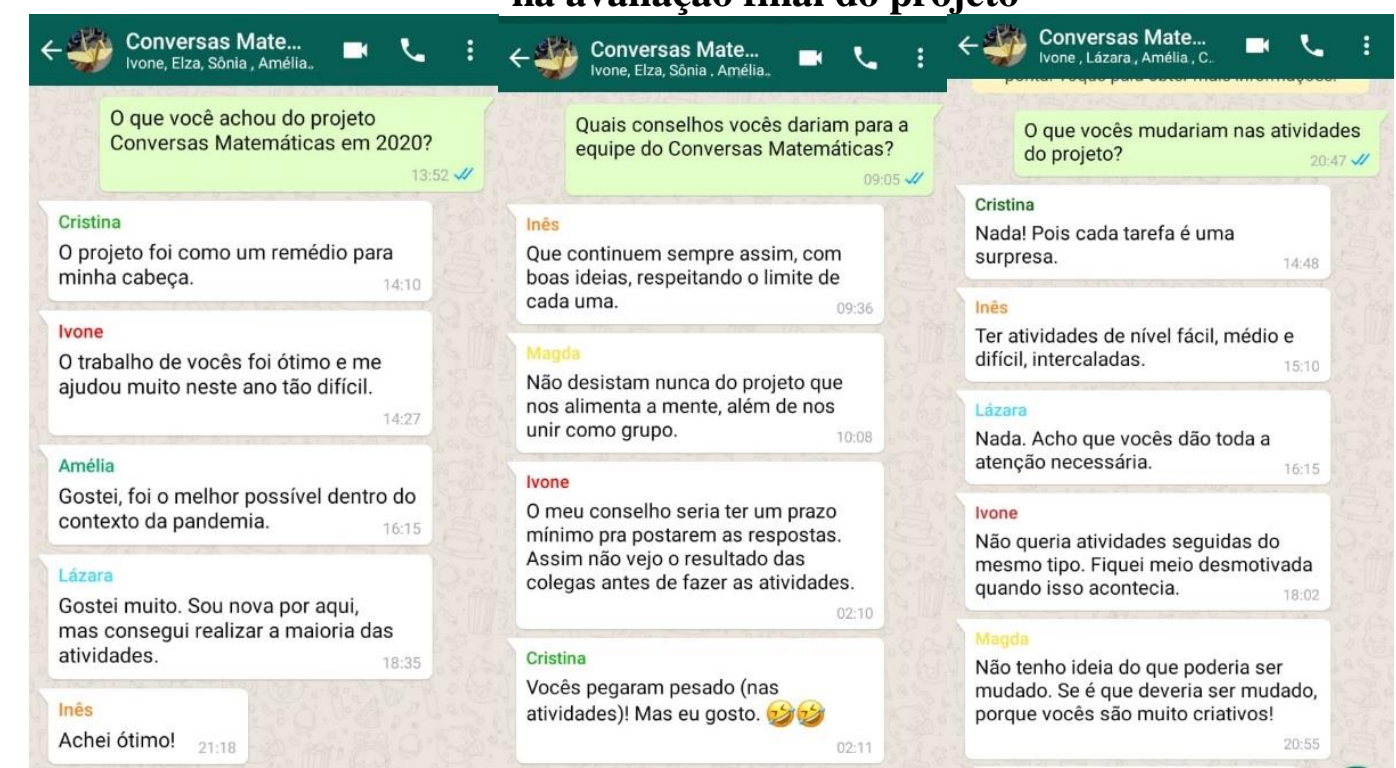

Fonte: Elaborado pelos autores.

A respeito da pergunta 1 , destacamos as falas da participante Cristina, que relaciona as ações do projeto a um "remédio para a cabeça" e de Ivone, que respondeu: "me ajudou muito neste ano tão difícil", ilustrando um dos objetivos do projeto que visa à melhoria na qualidade de vida das idosas participantes. O mesmo pode ser evidenciado na resposta de Magda à pergunta 2: "Não desistam nunca do projeto que nos alimenta a mente, além de nos unir como grupo", onde a questão do estímulo cognitivo apareceu novamente, e, também, o convívio social e as relações de grupo que transpassa as atividades realizadas.

Podemos notar, ainda, o reconhecimento de uma das idosas referente às dificuldades que o novo formato apresentou diante da situação adversa em que nos encontramos, limitando as interações por conta da mudança nos canais de comunicação, e Amélia alegou que gostou: “foi o melhor possível dentro do contexto da pandemia". Lázara, por sua vez, lembrou que foi uma das participantes ingressantes em 2020, mas que conseguiu realizar a maioria das atividades e, assim como Inês, se mostrou contente com o que realizou.

A pergunta 2 foi proposta com o intuito de buscar soluções para eventuais problemas que pudessem ser levantados na pergunta 1. Como respostas, vemos o incentivo para a continuidade do projeto, sugestões relacionadas ao tempo para postagens - para que as respostas das colegas não influenciassem na execução da atividade - e o relato de Cristina de que “pegamos pesado". Sobre este último comentário, ressaltamos que, tendo em vista nossos

Revista Extensão \& Cidadania, v. 9, n. 15, p. 27-45, jan./jun. 2021. 
pressupostos de criação de cenários para investigação, as atividades com esta característica demandavam uma postura mais ativa das idosas, sendo que algumas que já participavam do projeto estavam acostumadas, e outras não, e pode ter acontecido que isso se tornou mais exaustivo em algumas situações.

Já na pergunta 3, algumas idosas declararam que não mudariam nada no projeto, afirmando que a equipe sempre as surpreendia e que formávamos um grupo bastante criativo. E outras participantes disseram que poderíamos intercalar atividades fáceis, médias e difíceis, ou ainda, evitar o envio de atividades semelhantes ou repetidas em semanas seguidas, pois isso desmotivaria a participação delas. Essas falas nos chamou a atenção, porque sempre buscamos uma forma de intercalar diferentes atividades. Entretanto, em 2020, houve situações em que partes de uma mesma atividade ficaram parecidas, como é o caso da atividade "Matemágica", que consistia em adivinhar a idade das idosas e outros números pensados por elas e que, aparentemente, gerou incômodo em Inês e Ivone. Essas falas são lidas por nós como aprendizados para a elaboração e envio das atividades na próxima versão do projeto que, provavelmente, iniciará de forma remota, devido à velocidade de cobertura vacinal no Brasil.

Figura 6 - Respostas das idosas em relação às perguntas 4, 5 e 6 na avaliação final do projeto

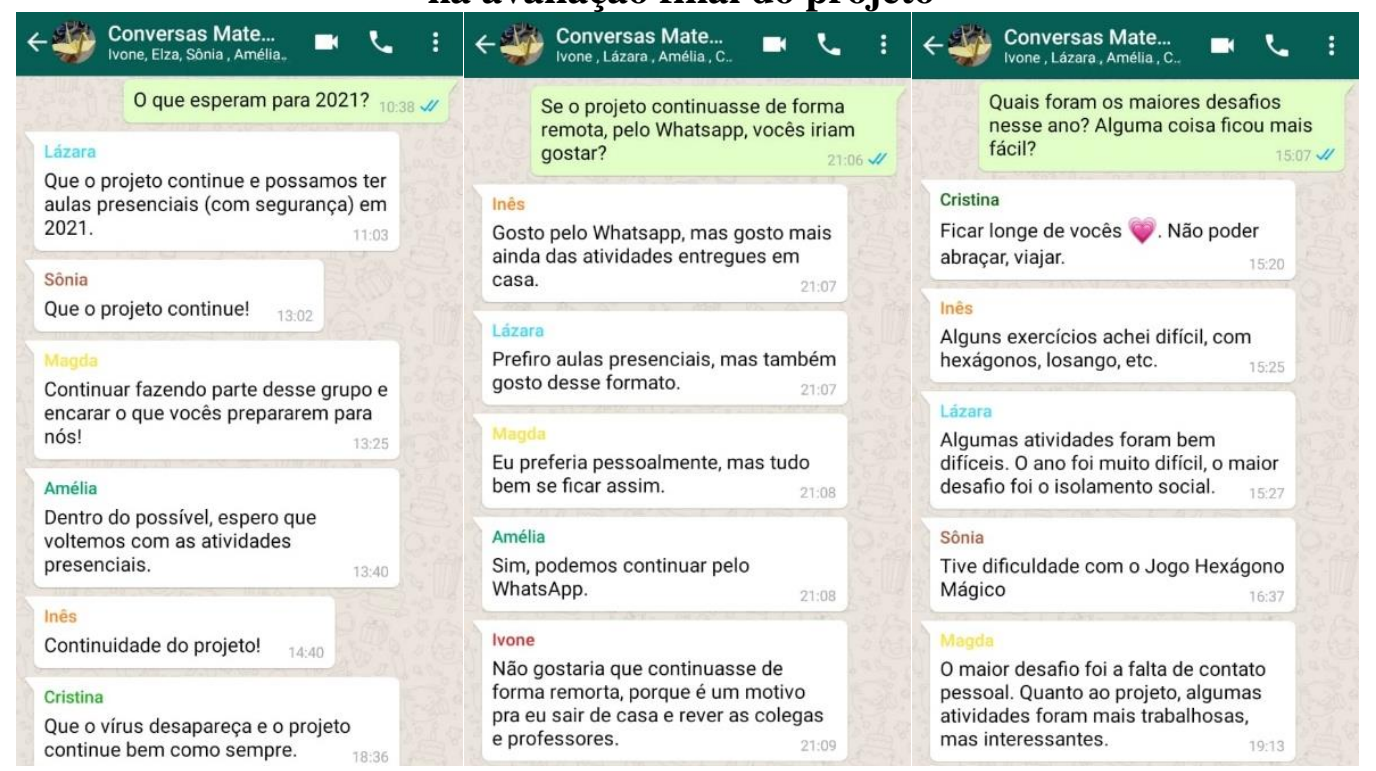

Fonte: Elaborado pelos autores.

$\mathrm{Na}$ pergunta 4, a maioria das idosas respondeu que esperava que o projeto pudesse continuar. Porém, além dessas respostas, algumas falas se destacaram, como, por exemplo, a

Revista Extensão \& Cidadania, v. 9, n. 15, p. 27-45, jan./jun. 2021. 
de Cristina: "Desejo que esse vírus desapareça e que o projeto continue bem, como sempre foi. E que Deus nos abençoe com um ano melhor e pessoas melhores". Pois, além de responder o que espera do projeto em 2021, disse também sobre sua expectativa em relação ao ano e às pessoas. Lázara e Amélia disseram que esperam que o projeto voltasse de forma presencial, dentro do possível, com todos os cuidados necessários. O que nos mostra que, mesmo entregando atividades em casa e conversando com elas pelo grupo de WhatsApp e por ligações, elas sentiam falta do contato presencial com a equipe do projeto e as participantes.

$\mathrm{Na}$ avaliação final do projeto, também observamos uma demanda das idosas por sua continuidade em 2021. Neste sentido, com base na pergunta 5, elas destacaram que preferiam atividades presenciais, pela oportunidade de contato com as colegas e com a equipe. Entretanto, as participantes afirmaram que, se necessário, as atividades poderiam ser executadas remotamente, até que fosse possível nosso retorno ao formato presencial. Elas destacaram, ademais, que gostariam de continuar recebendo algumas atividades impressas em domicílio. Isso ficou bastante evidente na fala de Inês: "Gosto das atividades pelo WhatsApp, mas receber pela correspondência no papel (impressa), eu gostei mais, pois podemos guardar e utilizar com os amigos e familiares". Já Ivone disse que "não gostaria que continuasse de forma remota, pois [o projeto] é um motivo para [ela] sair de casa e rever as colegas e os(as) professores(as)". Nessas falas notamos também uma esperança das idosas em ter o projeto no seu formato presencial em 2021.

Em relação à pergunta 6, obtivemos diferentes e interessantes respostas. Como perguntamos sobre o ano de 2020, algumas idosas apontaram aspectos relacionados à pandemia e ao isolamento social. Já outras destacaram desafios e facilidades relacionadas às atividades do Conversas Matemáticas. No que tange aos desafios impostos pela pandemia, com base na pergunta 6 , as idosas destacaram o isolamento social e as impossibilidades geradas por ele como os mais impactantes. Para elas, a falta de contato com a equipe e com as colegas foi um grande desafio em 2020. Já em relação ao projeto, as idosas apontaram atividades e jogos que consideraram mais desafiadores, como o "Jogo Hexágono Mágico" e o "Quebra-Cabeças com Hexágonos". Outras afirmaram que algumas atividades foram mais difíceis ou trabalhosas, mas que acharam interessantes.

Nesse sentido, a fala de Amélia nos chamou a atenção, pois segundo ela: "O maior desafio foi fazer as atividades sozinha. A interação é muito importante, principalmente para não desistirmos com as dificuldades". Para nós, esta última fala é expressiva no sentido da

Revista Extensão \& Cidadania, v. 9, n. 15, p. 27-45, jan./jun. 2021. 
importância de ter pessoas para dialogar enquanto se engajam em investigações matemáticas. Mesmo com o grupo de WhatsApp, a execução das atividades ocorria de forma individual na maioria dos casos e acreditamos que a formulação de questões e a busca por explicações sem a interação com uma pessoa tenha tornado o processo investigativo mais difícil para as idosas.

As idosas falaram mais a respeito dos desafios do que dos pontos que acharam mais fáceis em 2020. Sobre as facilidades, algumas disseram que também houve jogos fáceis, como o "Jogo do L" e o "Jogo das Quatro Cores". Também falaram sobre a facilidade em receber as atividades, como destacou Magda: "Ficou mais fácil receber as atividades pelo WhatsApp e em casa, mas acho que precisamos, e nos faz falta, a locomoção de um lado para o outro". A partir dessas respostas, observamos que as participantes produziram diferentes significados para a pergunta, considerando tanto aspectos relacionados ao projeto e às atividades voltadas para a matemática, quanto à vida pessoal e à situação de pandemia enfrentada em 2020. Neste sentido, fica claro o impacto social do projeto Conversas Matemáticas, pois as idosas destacam a ausência do contato físico, dos abraços e das viagens no cotidiano delas. De modo geral, elas apresentam o isolamento social como um grande desafio.

Outro ponto mencionado pelas idosas foi a atenção e o cuidado que a equipe teve com o grupo participante. Elas se sentiram acolhidas e valorizaram o posicionamento dos integrantes do projeto, agradecendo pelo carinho, pelas conversas e também pelos aprendizados.

Figura 7 - Respostas das idosas em relação à pergunta 7 na avaliação final do projeto

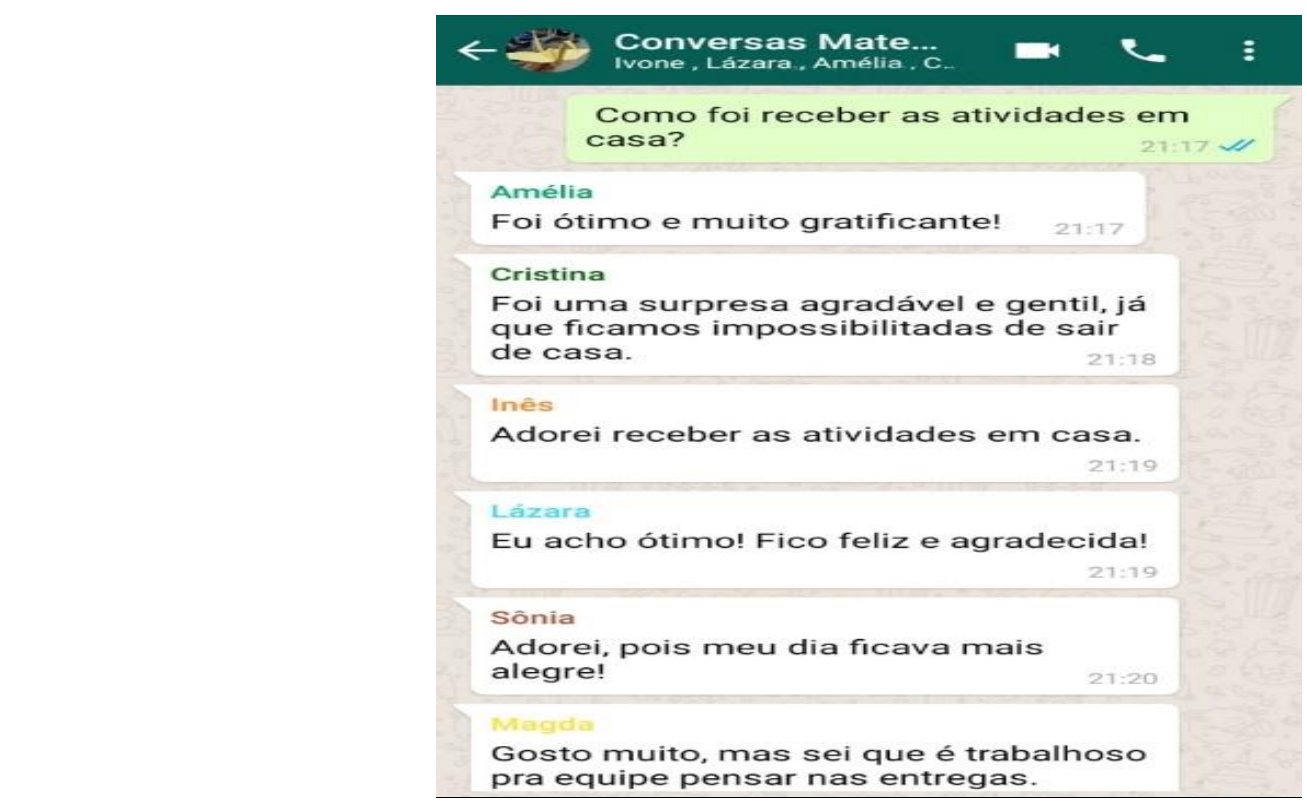

Fonte: Elaborado pelos autores.

Revista Extensão \& Cidadania, v. 9, n. 15, p. 27-45, jan./jun. 2021. 
Quanto às respostas dadas à pergunta 7, todas disseram que gostaram dessa iniciativa da equipe do projeto. Sônia disse que sempre que recebia as atividades, seu dia ficava mais alegre. Inês, Lázara e Amélia afirmaram que é algo gratificante. Além disso, Magda justificou: "Gosto muito de receber as atividades em casa porque posso ver pelo menos um de vocês de vez em quando." Dessa forma, podemos perceber, novamente, que elas sentiam falta de ter contato com a equipe.

A partir das análises das respostas das idosas, consideramos que o Conversas Matemáticas se apresenta, de fato, como um projeto voltado para uma educação pela matemática como, também, um meio para que interações e inclusão social ocorram. Especialmente em 2020, houve maior demanda por conversas relacionadas ao cotidiano e à vida pessoal das idosas e, consequentemente, o projeto se apresentou como um dos poucos espaços para interação social e dialógica das participantes.

A equipe também confeccionou um Caderno de Férias, que desde as outras versões do projeto é impresso e entregue às idosas no mês de dezembro para que possam se manter em atividade até o início de nova versão do projeto. Dentre as participantes, 13 quiseram receber o material. As quatro idosas que optaram por não aceitar a apostila afirmaram que estavam engajadas em outras atividades durante as férias, como viagens, artesanatos, grupos de oração, dentre outras.

Nesse material, inserimos atividades envolvendo assuntos abordados no decorrer do ano (Quadro 1), incluindo história da matemática, jogos, desafios matemáticos e curiosidades sobre a matemática. Houve ainda um cuidado na confecção do material para não tornar as atividades repetitivas, reformulando e adequando os jogos. Não foram disponibilizados gabaritos das atividades, pois esperamos que as idosas permaneçam com o interesse em manipular o material e investigar o que está sendo proposto, compartilhando seus argumentos, favorecendo o diálogo com a equipe e entre as colegas no período de férias. Em outros anos, o Caderno de Férias virava motivo para o encontro das idosas. Não obtivemos, ainda, notícias de como elas estão lidando com ele neste período pandêmico.

Revista Extensão \& Cidadania, v. 9, n. 15, p. 27-45, jan./jun. 2021. 


\section{Considerações finais}

Neste artigo, descrevemos o projeto Conversas Matemáticas em um contexto de pandemia, fazendo uma análise dele a partir das avaliações das idosas participantes. Foi abordado, inicialmente, o projeto, seus pressupostos teóricos e as adaptações ocorridas, na qual utilizamos o WhatsApp para realizar as interações e as atividades com as idosas. Também entregamos atividades em suas casas e realizamos ligações para elas.

Considerando esse cenário ainda pouco explorado, a experiência do projeto Conversas Matemáticas no ano de 2020 foi marcada pelo esforço da equipe em se aprofundar teoricamente para o planejamento e desenvolvimento das atividades no formato remoto. Inicialmente, encontramos dificuldades para a interação com as idosas no que diz respeito ao desenvolvimento das atividades propostas, o que tornou necessário o engajamento da equipe em buscar estratégias para a execução do projeto. Para isso, os integrantes se dedicaram à leitura/releitura e utilização de estudos relacionados à criação de cenários para investigação (SKOVSMOSE, 2000), comunicação e produção de significados (LINS, 1999), ao diálogo (MILANI, 2017) e, também, educação matemática com idosos (LIMA, 2015; SILVA; SILVA; JULIO, 2019; LIMA; PENTEADO; SILVA, 2019; JULIO; SILVA, 2019).

O projeto Conversas Matemáticas acontece em meio ou misturado com tudo o que a vida traz e fazemos dela. No caso das participantes, diferentes vivências foram acontecendo, sendo algumas compartilhadas no grupo do WhatsApp, pelas ligações e até mesmo no momento das entregas de atividades em casa. Essas vivências geraram alguns efeitos na participação no projeto. Algumas participantes se distanciaram (ou, melhor dizendo, ficaram em silêncio), fazendo poucas ou nenhuma das atividades, mas permaneceram no grupo de Whatsapp, recebendo atividades, inclusive em casa, e conversando com os membros da equipe nos momentos de ligação telefônica. Outras participantes voltaram a fazer parte do projeto após as ligações e outras intensificaram suas participações, por ver no projeto uma forma de lidar com o isolamento e a depressão.

A vida acontece, nos acontece, e por nos acontecer trouxe uma série de vivências para a equipe do projeto, demandando um esforço de manter a interação também com assuntos que extrapolavam a matemática ou as investigações matemáticas e requeriam uma sensibilidade para lidar com essas situações (como morte, adoecimento e depressão) de forma a não afastar as participantes ou a retirar o sentimento de pertencimento ao grupo, ainda que estivessem em

Revista Extensão \& Cidadania, v. 9, n. 15, p. 27-45, jan./jun. 2021. 
silêncio no grupo do WhatsApp. Pelas análises dos relatos das idosas, em momentos avaliativos, notamos que elas apontaram dificuldades com algumas atividades e com a própria vida, ressaltaram a importância do projeto, mesmo que remotamente, porque as mantiveram ativas e com senso de pertencimento a algum grupo. Tudo isso nos proporcionou o conhecimento de aspectos importantes para serem melhorados na elaboração e desenvolvimento de atividades futuras, ficando evidente a necessidade da continuidade do Conversas Matemáticas, nos mostrando a existência de um impacto positivo nas vidas das participantes decorrentes de seu envolvimento no projeto.

\section{Agradecimentos}

Agradecemos à Pró-Reitoria de Extensão da Universidade Federal de Alfenas pelo apoio e financiamento, aos extensionistas que já atuaram no projeto pelo legado histórico e às idosas participantes por confiarem em nosso trabalho.

\section{Referências}

CARDOSO, R. F.; NEVES, S. M. F. C; LOPES, R. A.; SILVA, G. H. G.; JULIO, R. S. Criação de cenários para investigação remotamente com pessoas idosas em situação de isolamento social. In: Anais do II Encontro Nacional de Educação Matemática Inclusiva. SBEM, 2021 (no prelo).

FORPROEX. Extensão universitária: organização e sistematização. Belo Horizonte: Coopmed, 2007. 112 p. Disponível em: http://www.renex.org.br. Acesso em: 14 jun. 2021.

JULIO, R. S.; SILVA, G. H. G. Educação Matemática, Inclusão Social e pessoas idosas: uma análise do projeto Conversas Matemáticas no âmbito do Programa Universidade Aberta à Pessoa Idosa. Educação Matemática em Revista, v. 24, p. 52-70, 2019.

LIMA, L. F. Conversas sobre matemática com pessoas idosas viabilizadas por uma ação de extensão universitária. 2015. Tese (Doutorado em Educação Matemática) - Instituto de Geociências e Ciências Exatas, Universidade Estadual Paulista, Rio Claro, 2015.

Revista Extensão \& Cidadania, v. 9, n. 15, p. 27-45, jan./jun. 2021. 
LIMA, L. F; PENTEADO, M. G.; SILVA, G. H. G. "Há sempre o que ensinar, há sempre o que aprender: como e por que educação matemática na terceira idade? Bolema, v. 33, p. $1331-1356$.

LINS, R. C. Por que discutir teoria do conhecimento é relevante para a educação matemática. In: Maria Aparecida Viggiani Bicudo. (Org.). Pesquisa em Educação Matemática: concepções e perspectivas, São Paulo, v. 1, p. 75-94. 1999.

LOPES, R. A.; SILVA, G. H. G.; JULIO, R. S. Uma Experiência com Pessoas Idosas por Meio dos Poliminós e de Tecnologias Digitais. In: Anais do V Congresso sobre Tecnologias na Educação. SBC, 2020. p. 550-558.

LUDKE, M.; ANDRÉ, M. E. D. A. A pesquisa em Educação: abordagens qualitativas. São Paulo: EPU, 1986.

MILANI, R. "Sim, eu ouvi o que eles disseram": o diálogo como movimento de ir até onde o outro está. BOLEMA, Rio Claro, v. 31, n. 57, p. 35-52, 2017.

SILVA, G. H. G.; JULIO, R. S. Macroinclusões e microinclusões de pessoas idosas em um contexto da Educação Matemática. Perspectivas da Educação Matemática, v. 11, p. 628$648,2018$.

SILVA, R. N.; SILVA, G. H. G.; JULIO, R. S. Educação matemática e atividades investigativas com pessoas idosas. Revista Pesquisa e Debate em Educação, v. 9, n. 1, p. 560-587, 2019.

SILVA, N.; SILVA, G. H. G.; JULIO, R. S. Contribuições para a formação inicial de professores de matemática a partir de seu envolvimento em um projeto extensionista direcionado ao público idoso. Bolema, Rio Claro, 2021 (no prelo).

SIMÕES, C. C. S. Relações entre as Alterações Históricas na Dinâmica Demográfica Brasileira e os Impactos Decorrentes do Processo de Envelhecimento da População. Rio de Janeiro: IBGE, Coord. População e Indicadores Sociais, 2016.

SKOVSMOSE, O. Cenários para investigação. BOLEMA, Rio Claro, v. 13, n. 14, p. 66-91, 2000.

SKOVSMOSE, O. O que poderia significar a educação matemática crítica para diferentes grupos de estudantes? Revista Paranaense de Educação Matemática, v. 6, p. 18-37, 2017.

Recebido: 09.03.2021

Aceito: 21.06 .2021

Revista Extensão \& Cidadania, v. 9, n. 15, p. 27-45, jan./jun. 2021. 